\title{
Relatos de caso: para além das normas, a coerência e a congruência
}

Ricardina Barroso*

Que todo o nosso conhecimento começa pela experiência, disso não existe qualquer dúvida. ${ }^{1}$

Contar histórias é uma forma de trocar experiências e, nesse sentido, cada relato deve conter os detalhes suficientes para que a experiência - no sentido de conhecimento imediato de uma realidade - possa de facto ser partilhada. Os detalhes podem reportar-se à história propriamente dita, mas também às dúvidas, questões e comentários que aquela experiência concreta suscitou em nós.

A reflexão sobre a prática clínica é uma actividade essencial a quem presta cuidados médicos e traduz a capacidade de aprender ao longo do tempo, com os seus próprios erros e com os seus êxitos. Sem essa reflexão não há lugar a dúvidas, nem a interrogações que são o motor de procura de novos conhecimentos. ${ }^{2}$

Adoecer é mais que a própria doença. ${ }^{3}$

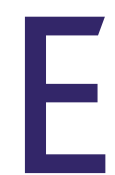

m 2001, Miguel Melo referia nas páginas desta Revista que "a comunicação de um Relato de Caso não exige apenas a vontade de partilhar a informação e a capacidade para a descrever", é necessário que reúna um conjunto de outros requisitos, designadamente que "transmita algo de novo e relevante com potencialidade para modificar a prática clínica". ${ }^{4}$

De modo inovador entre nós, orientou-nos na resposta às questões da relevância (Que tipo de relatos de caso merecem/devem ser comunicados), do formato (Como estruturar um relato de caso) e das especificidades do processo de publicação.

Em 2002, em carta dirigida ao Director, Juan Gérvas enfatizava a necessidade de ajustar os casos clínicos apresentados à realidade do trabalho diário em medicina geral, salientando a importância da descrição do processo de adoecer, de uma pessoa ou grupo, in-

*Médica de Família, Assistente Graduada Sénior aposentada. cluindo as vivências e as modificações que provoca no comportamento individual e familiar. ${ }^{3}$ Salientava, assim, os aspectos inerentes ao processo de prestação de cuidados, nas perspectivas do doente e do médico, em complementaridade das questões ligadas exclusivamente à doença. Defendeu, argumentando com base em exemplos da prática diária, que um relato de caso de medicina geral deveria incluir dados sobre o agregado familiar do paciente e sobre o impacto da doença nessa estrutura, a ocupação profissional do paciente e a repercussão da doença nessa ocupação, a situação sociocultural do paciente, as barreiras à acessibilidade, o processo de diagnóstico, o processo terapêutico, a repercussão da doença no profissional e, por fim, uma nota acerca da evolução do paciente. ${ }^{3}$

Estes dois textos constituíram-se como marcos de referência na Medicina Geral e Familiar Portuguesa, actuais ainda hoje.

A literatura médica mundial avançou também neste domínio e em 2013 foram publicadas orientações detalhadas para a elaboração de relatos de caso, incluídas na plataforma EQUATOR-The CARE guidelines: consensus-based clinical case reporting guideline.$^{5-6}$ Ao mesmo tempo, as revistas com revisores interpares foram sendo encorajadas a fomentar o uso das normas orientadoras no processo de análise dos casos submetidos, verificando-se em todo o mundo um aumento de rigor na selecção dos relatos de caso publicados. ${ }^{7}$

No decurso dos últimos dezasseis anos foram publicados na RPCG/RPMGF noventa relatos de caso. Entre 2000 e 2010, a média era de dois relatos de caso por ano. A partir de 2011 foi aumentando de modo progressivo e continuado o número de relatos de caso publicados (oito em 2011, dezasseis em 2015). A tendência, verificada entre nós, acompanhou a realidade mundial. Esta progressão no número de relatos de caso publicados - normas cada vez mais detalhadas e espe- 
cíficas, recomendações aos revisores para que analisem os casos e verifiquem o cumprimento das normas de modo exaustivo - tem sido também acompanhada pela identificação de especificidades relacionadas com os diferentes ramos do saber e exercício médicos. Estão publicadas orientações específicas para os relatos de caso em cardiologia, pediatria, entre outras, que têm subjacente a ideia de que existem particularidades em cada especialidade, suficientemente importantes para a distinguir das restantes e necessárias à caracterização da qualidade do pensar e agir na clínica.

Éneste ponto que urge reflectir sobre a coerência entre os princípios que norteiam a prática da medicina geral e o conteúdo e descrição dos casos publicados entre nós. A leitura de noventa casos publicados desde o início do século conduzem a algumas questões que estão para além das normas. Verificamos que muitos casos são exemplos bem conseguidos do que se advoga como praxis, outros são demonstrativos das interrogações aqui propostas.

Defendendo o primado do doente e a sua centralidade na consulta, no processo diagnóstico e no processo terapêutico, a narrativa escrita que produzimos tem de ser coerente com o conceito de medicina centrada no paciente. O doente não pode surgir como uma figura ilustrativa, um mero adereço, que apenas dá existência a um conjunto de ideias vulgares sobre um problema de saúde. A coerência com os princípios que definem a nossa especialidade obriga-nos a caracterizar o doente segundo todos os itens das normas, mas também a conduzir a descrição relatando o seu pensar, sentir e vontade, tornando-o presente enquanto ser singular. E, se verdadeiramente praticamos a medicina centrada no paciente, os nossos relatos têm de dar conta das inflexões feitas, de como incorporámos no processo de diagnóstico as ideias e os receios do doente, de como compatibilizámos no processo de decisão as suas crenças e escolhas.

A ética é, indiscutivelmente, um aspecto ligado à boa prática clínica. Como um dos aspectos éticos a cumprir, todos os casos actuais referem a existência do consentimento informado, sendo este dado pelo doente no pressuposto de que não será identificado e de que aspectos íntimos, irrelevantes muitas vezes para as questões em apreço, não serão divulgados. Com surpresa podemos verificar que, não raras vezes, a identificação do doente é fácil e que o relato inclui informação íntima irrelevante para o problema em discussão. Os casos devem cumprir os procedimentos éticos considerados adequados no exercício profissional (sem decisões tomadas por outros, em nome dos doentes, no seu suposto benefício; sem partilha de informação pessoal com outros elementos da família). A interferência de familiares no processo diagnóstico e a tomada de decisões pelo doente, sem o seu conhecimento e sem a sua anuência explícita, constituem questões éticas da maior importância, que necessitamos de identificar, analisar e discutir. Em ética, designadamente na clínica, as decisões e as acções envolvem questões complexas, em que se sobrepõem direitos individuais, princípios morais e deveres deontológicos dos próprios médicos. Entre estes deveres, existe o de não emitir juízos de valor sobre escolhas de vida do doente, sendo por isso necessário tornar patente que foram respeitadas as suas preferências e a sua privacidade. Encontram-se algumas descrições onde é claro um julgamento não médico, inferências moralizadoras, deixando antever ideias preconceituosas e de valor sobre acções ou opções do doente.

Em 2006, Cohen ${ }^{8}$ defendia que, no sentido de limitar a identificação do paciente, deveriam ser omitidas, dos relatos de caso, as iniciais do doente, a data de nascimento e, do mesmo modo, as datas de admissão, de consultas ou de outros eventos. Acrescentarei que também a localização muito precisa da naturalidade e da residência do doente, agregadas entre si e ligadas a outros elementos, por vezes invulgares, da história clínica permitem a sua identificação clara e precisa. Nestas situações não são os nomes fictícios que constituem qualquer garantia de anonimato ou de confidencialidade. Acresce que a designação dos autores, com referência ao local onde exercem, identifica pequenas comunidades e nelas, facilmente, o doente em causa.

A presença de pormenores excessivos na caracterização, a ausência de reflexão sobre o modo como se valorizou um detalhe chave para o raciocínio diagnóstico, a discussão repetitiva e a ausência de reflexão crítica constituem incongruências frequentes que precisam de ser equilibradas na fase de planeamento e revisão da escrita.

Ao relatar um caso desejamos transmitir aos outros uma informação nova, relevante, que nos conduziu num caminho inabitual e que consideramos útil. Para 
além da leitura imediata, na data e número da revista em que foi publicada, ambicionamos que outros, com dúvidas ou questões semelhantes, possam juntar os seus casos ao nosso. O único meio de conseguir concretizar essa ambição é escolher criteriosamente as palavras-chave. Para isso uma questão clínica bem construída é fundamental para a selecção dos termos descritores $(\mathrm{MeSH})$ a usar. ${ }^{4}$

A escrita (e a leitura) são instrumentos de (auto)conhecimento. ${ }^{9} \mathrm{~A}$ reflexão que antecede e acompanha a escrita de um caso, de uma experiência (ensaio/prova) e se prolonga para além no tempo, é vital para qualquer médico. Permite um acrescento de saber, de dúvida e de mais saber, numa espiral de crescimento com um potencial de mudança que nenhum outro método possui. Ganharemos saber, ensinaremos atitudes e valore ${ }^{10}$ publicando mais relatos de caso. $\mathrm{O}$ dever de os analisar e discutir, encontrando velhos problemas e novas soluções, novos problemas e velhas soluções, é de todos, sem perder de vista os princípios que nos norteiam - o respeito pela individualidade e pela liberdade de cada ser humano e o dever de procura, para cada um, de um cuidado humanizado, dirigido, actuante, equitativo e digno.

\section{REFERÊNCIAS BIBLIOGRÁFICAS}

1. Kant I. Crítica da razão pura. $6^{\text {a }}$ ed. Lisboa: Fundação Calouste Gulbenkian; 2008. ISBN 9789723106237
2. Barroso R. Casos clínicos e relatos de caso: um modo de reflectir a prática clínica. Rev Port Clin Geral. 2000;16(2):99-100.

3. Gervas J.A apresentação de casos clínicos em medicina geral. Rev Port Clin Geral. 2002;18(2):129-30.

4. Melo M. Elaboração de relatos de casos [Elaborating case studies]. Rev Port Clin Geral. 2001;17(6):487-92. Portuguese

5. Gagnier JJ, Kienle G,Altman DG, Moher D, Sox H, Riley D, et al. The CARE guidelines: consensus-based clinical case reporting guideline development. BMJ Case Rep. 2013 Oct 23;2013:bcr2013201554.

6. Gagnier JJ, Kienle G,Altman DG, Moher D, Sox H, Riley D, et al. The CARE guidelines: consensus-based clinical case reporting guideline development [Internet]. EQUATOR Network; 2016. Available from: http://www. care-statement.org/downloads/CAREchecklist-Eng-20160131.pdf

7. Hirst A, Altman DG. Are peer reviewers encouraged to use reporting guidelines? A survey of 116 health research journals. PLoS One. 2012;7(4):e35621.

8. Cohen H. How to write a patient case report. Am J Health Syst Pharm. 2006;63(19):1888-92.

9. Fernandes I, Cabral MJ, Casal T, Correia A, Almeida D. Contar (com) a medicina. $2^{a}$ ed. Lisboa: ULICES/Edições Pedago; 2016. ISBN 9789898655516

10. Hensel WA, Rasco TL. Storytelling as a method for teaching values and attitudes. Acad Med. 1992;67(8):500-4.

\section{CONFLITOS DE INTERESSE}

A autora declara que é revisora da RPMGF.

\section{ENDEREÇO PARA CORRESPONDÊNCIA}

ricardinabarroso@gmail.com

Artigo redigido ao abrigo do acordo ortográfico anterior a 1990. 